trying to produce a simplified picture has its pitfalls. Certainly, taking a 32-year 'window of observation' for analysis produces a paradox. Patterns may be more discernible over a long-term but the amount of data available often makes analysis complex. Furthermore, there are dangers of being trapped by the statistical procedures one adopts. Identifying four rather different domains in which those convicted of sex offences seem to operate, we have provided a somewhat essentialist stance. In brief, our analysis may suggest that lives are rather more static than they really are. In fact, lives can be quite dynamic. Perhaps persons whom we have deemed as essentially violent or acquisitive or deceptive or homosexual do change over time and what we have deemed as their 'master status' may not remain constant. Nevertheless, we suggest that this analysis helps to guard against the rather narrow focus on sexual offending in isolation which current theory and practice seem to encourage. \&

\section{Keith Soothill}

Professor of Social Research, Department of Applied Social Science, Lancaster University

\section{and Brian Francis}

Director of the Centre for Applied Statistics, Lancaster University

The authors are currently completing a study of homicide comparing Scotland and England \& Wales. Keith Soothill is the editor of a book just published, Criminal Conversations: An Anthology of the Work of Tony Parker (London: Routledge, 1999).E-mail:k.soothill@lancaster.ac.uk

This study is derived from work for the ESRC project, Criminal Careers and Sex Offending (ESRC Grant No. R000 23 6237). The assistance of the Home Office, together with colleagues Elizabeth Ackerley and the late Barry Sanderson, is much appreciated. An earlier version was presented in a paper at the 12 th International Congress on Criminology, 24-29 August 1998, Seoul, Korea.

\title{
Model contracts in the construction industry
}

\author{
by Geoff Haley
}

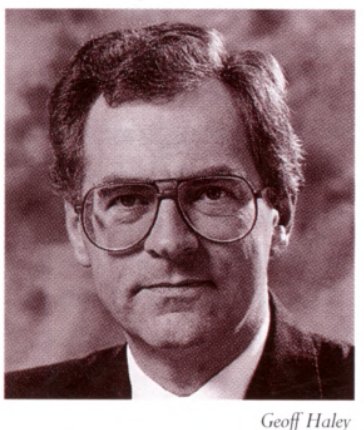

The Private Finance Initiative (PFI) was launched in 1992 with the aims of improving the quality and quantity of public sector capital projects and of developing higher quality and more cost-effective public services through partnerships with the private sector. The scheme is based on the premise of procurement of a high capital value asset being passed to the private sector together with the attendant risks. UK Government Departments must initially examine the PFI potential of all capital projects and if practicable, follow the PFI route. This has led to PFI being extended to a number of sectors in the UK including schools, hospitals, roads, police stations and government accommodation.

Under the PFI, the concept of Design Build Finance Operate (DBFO) was introduced as an alternative procurement method for the public sector. This involves a public sector body purchasing a capital-intensive service from a private sector provider, which includes provision and maintenance, under a long-term contract. The public sector pays for the service in specific payments as defined in the contract which will depend on the provider's performance and/or usage of the service. The provider will assume responsibility for investing in the capital assets, financing that investment and managing the facilities to the level of service specified by the public sector.

\section{FORCE MAJEURE}

Force majeure is a concept widely understood and accepted throughout the world, although the definition and interpretation of the circumstances differ from one jurisdiction to another as do the legal consequences. It is generally accepted as being the circumstance under which the party suffering from a non-default incident, unforeseen and outside the control of the parties (i.e. usually the private sector partner) can be excused from further performance of the contract. 


\section{The FIDIC model}

Under FIDIC, force majeure is defined as

'an event beyond the control of the Employer and the Contractor, which makes it impossible or illegal for a party to perform, including but not limited to:

(a) act of God;

(b) war, hostilities (whether war be declared or not), invasion, act of foreign enemies, mobilisation, requisition;

(c) rebellion, revolution, insurrection, or military or usurped power, or civil war;

(d) contamination by radio-activity from any nuclear fuel, or from any nuclear waste from the combustion of nuclear fuel, radio-active toxic explosive nuclear component of such assembly;

(e) riot, commotion or disorder, unless solely restricted to employees of the Contractor or of his subcontractors.' (FIDIC, Conditions of Contract for Design Build and Turnkey, First Edition, 1995)

If any of the above events occur, neither party shall be considered in default or in contractual breach to the extent that their performance of the contract is hampered by the event in question.

When a force majeure event occurs, contractors must endeavour to continue to perform their obligations under the contract but only so far as is reasonably practicable. If, as a result of the 'force majeure', a contractor suffers loss or damage while trying to comply with the contract, then, to that extent, the contractor will be indemnified for the extra cost incurred. If the 'force majeure' delays the contractor's performance of the contract, then the contractor can be given extra time to perform.

Irrespective of any extension of time, if the effect of a force majeure event persists for more than 182 days, either the employer or the contractor may give notice of termination of the contract. It is suggested, however, that the 182-day time frame be amended where appropriate. This would probably be required by most contractors, who would find 182 days far too long.

If the contract is terminated the employer shall value the work done in the following way:

(a) the amount payable for any work carried out for which a price is stated in the contract;

(b) the cost of plant and materials ordered for the works which have been delivered to the Contractor, or of which the Contractor is liable to accept delivery: such plant and materials shall become the property of (and be at the risk of) the Employer when paid for by the Employer, and the Contractor shall place the same at the Employer's disposal;

(c) any other cost or liability which in the circumstances was reasonably incurred by the Contractor in the expectation of completing the works (i.e. third party liability);

9d) the reasonable cost of removal of temporary works and Contractor's equipment from site and the return of such items to the Contractor's works in his country (or to any other destination at no greater cost); and

(e) the reasonable cost of repatriation of the Contractor's staff and labour employed wholly in connection with the works at the date of such termination.' (FIDIC, Conditions of Contract for Design Build and Turnkey, First Edition, 1995)

\section{$U K$ approach to force majeure and project finance}

In the UK the Law Reform (Frustrated Contracts) Act 1943 (the 'Act') will apply unless the contract incorporates a provision dealing with the possible events of force majeure and their effect upon the performance and termination of the contract. The contract will be deemed 'frustrated', i.e. incapable of performance. However, there will be no contractual provision stating how long an event has to persist before the contract can be deemed frustrated.

A widely-drafted force majeure clause, similar to the FIDIC model, eradicates to a large extent the uncertainty of the Act and also gives the respective parties control over the circumstances surrounding such an event.

The FIDIC model clause applies to a project during the construction period. Under the UK PFI, the clause would apply to the design, construction and provision of service period, which could be 25 to 40 years.

As a public/private partnership, and in view of the length of the potential service period, it is important that the parties to a PFI contract know as clearly as possible what will happen at any given point in the contract period (being both the construction period and the provision of service period). Building an effective working relationship over the span of the contract is also imperative, which is aided at the outset by a recognition of the private sector's need for certainty in this respect.

As the UK PFI projects involve the introduction of equity and, in the main, bank debt, it is equally important for equity investors and bankers to be able to quantify the extent and circumstances of loss. This is much easier if an express contractual term sets out all the likely force majeure events.

The aim of a force majeure clause should therefore be to address risks that cannot be economically insured and to specify how those risks should best be managed.

HM Treasury's position Under the 'Basic Contractual Terms' published by the Private Finance Panel Executive and HM Treasury (21 October 1996), force majeure events are limited to:

- war, civil war, armed conflict or terrorist attack arising within and affecting the United Kingdom; or

- nuclear, chemical or biological contamination of the contractor's property arising from any of the events at (a) above.

(In this definition, 'the contractor' is used to define the Special Purpose Vehicle Company (SPV) created to design, construct and operate a facility, e.g. a prison, hospital or toll road.)

The Treasury's definition of force majeure is extremely narrow. The Treasury envisages that other circumstances that have previously come under force majeure will be dealt with separately under specific provisions within the contract.

An example of how this approach may be implemented can be seen in the way in which the issue of extension to the concession period was dealt with in the two completed PFI prison projects. The contracts provided that if the opening of the facility was delayed by events such as strikes by third parties, civil commotion or exceptionally adverse weather conditions, then the concession period would be extended, rather than the event in question giving rise to both parties being fully released from their obligations under the contract. 
The force majeure events should at this juncture be limited as far as possible to those defined by the Treasury as standard PFI practice. The consequences of force majeure should also be considered:

(1) Length of time before contract is terminated. A relatively short 'cure period' should be granted - perhaps six months, which is a reasonable mid-position and has been acceptable to bankers on other projects.

(2) Possible payment to private sector on the occurrence of a force majeure event.

(3) Suspension of performance regime in respect only of services that cannot be made due to the occurrence of an event of force majeure.

(4) Suspension of availability payment to the extent the event has rendered the premises unavailable.

(5) The party suffering the force majeure event (usually the SPV) to use best endeavours to remedy the situation.

Uninsured risks The Treasury approach to force majeure appears to work perfectly well for the eventualities described. However, for other events often included under the force majeure head, but excluded by the Treasury definition, this approach may not work. Examples of such events are natural disasters (c.g. earthquake, volcanic eruption, etc.) and damage caused by articles falling from aircraft or the impact of satellites. Events such as these have the potential to be equally as devastating as the events included in the Treasury's definition of force majeure. If the latter definition of force majeure is to be used then the contract must recognise some other forms of cataclysmic events beyond the control of both parties and provide for a method of releasing the parties from their contractual obligations, or for events of a less cataclysmic nature, a method for adjusting the parties' obligations in a just and equitable manner.

One possible method of achieving this would be to classify such risks as 'uninsurable risks'. Such a title is a slight misnomer as, in fact, some of these risks may actually be insurable, albeit at a disproportionate cost. The consequences of an event of 'uninsurable risk' could be fixed by the contract to be less final and absolute as the consequences of an event of force majeure. For example, it could be provided that the obligations of the parties are suspended for the period while the risk operates, subject to negotiation between the parties as to how any resulting additional costs will be shared.

The contractual consequences of an 'uninsurable risk' event occurring may vary, depending on whether it occurs during the construction or operating phase of the project. For example, long delays during the construction phase could be compensated for by an adjustment to the availability payment over the remaining term of the agreement and/or an extension to the concession period. In the case of such events occurring during operation, another possible solution would be to suspend any monitoring and performance requirements.

If any bidder is forced to shoulder a high level of risk by a very narrow definition of force majeure, this will be reflected in the overall pricing of the bid. Extra insurance costs and/or contingency sums will have to be built into the pricing structure.

\section{CONTRACT TERMINATION}

Contract termination is a fundamental issue that must be examined in any contract, especially in construction contracts where the potential for default by either party is notorious. However, this is also an area of law where there are substantial differences between jurisdictions and where approaches thus vary considerably.

\section{Termination under FIDIC}

Under the FIDIC Form of Contract there are three possible termination scenarios:

- no default

- contractor's default

- employer's default

No default This is generally accepted to be covered by the force majeure clause that was examined above and by a change of law clause.

Contractor's default Under the FIDIC model, if a contractor fails to carry out any of his obligations, or if the contractor is not executing the works in accordance with the contract, then the employer may give notice to the contractor, requiring him to remedy his failure within a specified reasonable period. If the contractor:

(1) fails to comply with the above notice;

(2) abandons or repudiates the contract;

(3) without reasonable excuse fails:

(a) to commence the work in accordance with the contract;

(b) to procced with the works in accordance with the contract; or

(c) to demonstrate that sufficient design capacity is employed in the design of the works to achieve completion within the time for completion;

(4) becomes bankrupt or insolvent or goes into liquidation, etc.; or

(5) assigns the contract or subcontracts the works without the required consent;

then the employer may, after having given 14 day's notice to the contractor, terminate the contractor's employment under the contract and expel him from the site. The contractor shall not be released from any of his obligations or liabilities under the contract. The rights and authorities conferred on the employer, and the employer's representative, by the contract shall not be affected.

Under this clause, the employer can terminate the contractor's employment if any of the above occur. However the contractor is not in any way released from his contractual obligations or liabilities. It should also be noted that, under this clause, the employer has the option of removing the contractor from the site. This could, potentially, be very controversial since the contractor might want to challenge the termination and stay on site until a decision is reached on the matter. This is generally motivated by the fact that such challenges can be very time-consuming if they go to court or arbitration.

Under the FIDIC rules, termination payments are to be determined by the engineer after any termination by the employer. His duties include a valuation of the work carried out 
under the contract, unused and partially used materials, any equipment and any temporary works. The FIDIC model also provides that the employer is not liable to pay anything to the contractor until

'[the] expiration of defects liability period and thereafter until, costs of execution, completion and remedying of any defects, damages for delay in completion, if any, and all other expenses incurred by the employer have been ascertained and the amount thereof certified by the engineer.' (FIDIC Form of Contract, Fourth Edition, 1997)

Employer's default Under the FIDIC Form of Contract, the employer is in default if he:

- fails to pay the contractor the amount due under any certificate of the employer's representative within 42 days after expiry of the time stated in the contract within which payment is to be made (except for any deduction that the employer is entitled to make under the contract);

- becomes bankrupt or insolvent or goes into liquidation, etc.;

- consistently fails to meet the employer's obligations under the contract;

- assigns the contract without the contractor's consent; or

if a prolonged suspension affecting the whole of the works goes beyond that authorised in the contract, then the contractor may terminate his employment under the contract by giving notice to the employer. (Sub-clause (2) would be omitted if the employer was a government.)

The terms of employer's default are very similar to those used for contractor default. The terms of payment "on termination have one significant difference, however: in addition to those mentioned above the employer is also required to pay to the contractor 'the amount of any loss or damage to the contractor arising out of, or in connection with, or by consequence of such termination' (FIDIC Form of Contract, Fourth Edition, 1997

This means that the contractor should be able to claim both his consequential losses and his future loss of profits.

\section{Termination in UK PFI contracts}

In the event of contract termination, the contract must provide a mechanism to ensure that the SPV is compensated for the value of the project assets, plus other liabilities and expenses. In general, the SPV will suffer more loss on termination than the public sector, as the facility which it designs and builds, using its own and bank finance, will revert to the public sector on termination. The private sector's view is usually that where the termination is caused by circumstances within the control of the employer or government, the compensation payable should also include reimbursement of the equity investment in the SPV (sometimes including liabilities incurred towards third parties and the costs of demobilisation).

The SPV is likely to request compensation for:

- its cost in developing and constructing the project (where termination occurs during construction);

- outstanding borrowings, including interest and commission, and third party liabilities (where termination occurs during the operational phase);

- financing costs, interest and finance charges (e.g. breakage costs);

- a return on equity.
However, the public sector will wish to limit the above by:

- limiting compensation to the SPV in the event of SPV default and in the event of force majeure; and

- deducting losses suffered by the public sector:

The following are key issues.

Debt repayment Until the PFI market matures, debt providers will always push to be kept whole on termination. In the future this will no doubt change, but debt returns are at present not seen to be sufficiently high for such a significant risk to be taken on by the banks.

Reimbursement of equity investment The private sector view is usually that where termination is not caused by SPV default, the compensation payable should also include reimbursement of the equity investment in the SPV (sometimes including liabilities incurred towards third parties, or breakage costs, and the costs of demobilisation). This is often calculated on the basis of the deemed fair market value of the equity share capital in the SPV, taking into account the value of the contract before termination.

However, the public sector would wish to exclude return on equity and limit demobilisation/third party costs in the event of SPV default and force majeure.

Deducting losses In compensating the SPV for equity and/or loan repayments, the public sector will wish to ensure it is in turn compensated for its losses. However; the public sector should avoid deducting its losses from debt repayments, as the key aim in termination provisions is to facilitate repayment of principal debt, in order to improve the project's 'bankability'. Accordingly, any compensation provisions should not impinge on debt repayment.

Force majeure The SPV may argue that risk of force majeure events (for which commercially viable insurance is not available) cannot rest with the SPV, because banks will not lend to them unless they are confident that their debt will be discharged in full if the contract fails due to force majeure. Accordingly, debt repayments must be made. However, beyond that, mutual liabilities should be minimised. This means that the SPV should take on the risk of losing equity, and any further compensation provisions should be limited to direct losses only.

Employer default Where the employer is in default and the SPV decides to terminate the contract, compensation would be paid for the following:

- outstanding loan principal, together with interest and finance charges (e.g. breakage costs);

- fair market value of equity investment in the SPV on the basis of a going concern;

- other liabilities to third parties incurred by the SPV and committed as at termination date, including accrued dividends and interest on subordinated debt (if any);

- costs of demobilisation (including redundancy costs if TUPE does not apply);

- fees and expenses of any receivers appointed.

However the employer might require the option to nominate a third party to acquire the equity or to pay the equivalent sum to the SPV. If the former route was chosen then the employer would also pay to the SPV a sum sufficient to discharge outstanding debt, interest and finance charges. If the latter option was taken the employer would have the option to 'step in' 
and continue debt repayments, interest and financing charges, according to an agreed timetable.

The value of equity must be the fair market value, immediately prior to date of termination, as between a willing vendor and a willing purchaser, taking into account the net present value of the contract for the remainder of the contract period. The calculation must also take into account all rights, liabilities and obligations of the SPV immediately prior to the termination date.

SPV default The employer will be entitled to terminate the project agreement in the following circumstances:

- SPV insolvency;

- poor performance by the SPV (as defined by reference to persistent service failure or prolonged unavailability tests);

- other material breach of the project agreement by the SPV.

Compensation payable to the SPV should be calculated by using a valuation formula. The formula should not give rise to any obligation on the SPV to make a payment to the employer. The principle behind this is that the senior debt provider should always be made whole.

\section{CONTRACT VARIATION}

It is widely agreed and acknowledged that, due to the size, complexity and length of major construction contracts and, similarly, concession agreements, no agreement could ever cover or foresee all the possible changes that could affect a project. Because of this, it is generally accepted that it is necessary to incorporate a mechanism for the implementation of changes that are found to be necessary or desirable during both the construction and service provision phases.

\section{The FIDIC model}

Under the FIDIC Form of Contract, it is stated that:

'The Engineer shall make any variation of the form, quality or quantity of the works or any part thereof that may, in his opinion, be necessary and for that purpose, or if for any other reason it shall, in his opinion, be appropriate, he shall have the authority to instruct the Contractor to do and the Contractor shall do any of the following:

(1) increase or decrease the quantity of any work included in the contract;

(2) omit any such work (but not if the omitted work is to be carried out by the Employer or by another Contractor);

(3) change the character or quality or kind of any such work;

(4) change the levels, lines, position and dimensions of any part of the work;

(5) execute additional work of any kind necessary for the completion of the works; or

(6) change any specified sequence or timing of construction of any part of the works.

No such variation shall in any way vitiate or invalidate the contract, but the effect, if any, of all such variations shall be valued in accordance with the contract. Provided that where the issue of an instruction to vary the works is necessitated by some default of or breach of contract by the Contractor or for which he is responsible, any additional cost attributable to such default shall be borne by the Contractor.'
Under this clause the engineer's powers, as agent for the employer in this case, are very wide since he can order a variation or acquiesce a variation proposed by the contractor. The scope of the variations is also very wide since it covers form, quality and quantity of the works.

Under sub-clause 5, any 'additional work' is limited to 'any kind necessary for the completion of the work'. Thus, additional work for a purpose unconnected with the original concept, of unnecessary, could not be imposed and would have to be agreed by all the parties. However, what is 'necessary' or not is a matter to be decided by the engineer. In addition, the clause also gives the engineer discretion to order a variation if 'in his opinion' it is 'appropriate'. The fact that the necessity and appropriateness of the works are dependent on the engineer clearly demonstrates the huge discretion awarded to him and just how limited the contractor's powers are in this field.

One reason for this discretion is that the engineer is considered to be the most suitable person to take the decisions. This is because he is an expert in the field who is involved in the project and, most importantly, because he is perceived as impartial since he is between the employer and the contractor. However this neutrality has often been challenged by both parties, depending on who employs and pays the engineer

\section{Differences under $U K$ PFI}

UK variation clauses in PFI projects are somewhat different from those proposed by FIDIC. The discretion and the powers of the employer and the engineer are far more restrictive. This is illustrated by the following, which is a typical Build Own Operate Transfer (BOOT) project clause:

'The Authority shall be permitted to vary the Design Documents and/or the Works and in such circumstances the following procedure shall apply:

(1) the Authority shall submit details of the Proposed Variation to the SPV who shall provide an estimate of the value of the Proposed Variation and an estimate of the length of any extension of time and the amount of any loss and or expense to which the SPV might become entitled in respect of the Proposed Variation within [ ] Business Days of the Authority's original notification of the Proposed Variation;

(2) if the estimate prepared by the SPV under Subclause (1) is accepted by the Authority, the Authority will issue an instruction to the SPV confirming the Variation and the Authority will then grant an extension of time and/or give affect to the agreed valuation as detailed in the estimate.'

Here the agreed amount of loss and expense can be paid as a lump sum or added to the revenue stream as an increase in the payments due to the SPV during the 'operation and maintenance' phase.

'(3) in the event that Agreement cannot be reached as to the estimate referred to in Subclause (1), and the Authority wishes to proceed with the Proposed Variation, then the matter shall be determined by the Disputes Resolution Procedure;

(4) for the avoidance of doubt, any change in Legal Requirements during Phase 1 apart from those specified in Schedule 9 (for which the SPV shall not be compensated) shall be treated as a Confirmed Variation Order for all the purposes of this Clause.' 
This clause allows the authority to amend the design and indeed the elements of the works in accordance with the prescribed procedure. The procedure suggested places an obligation on the SPV to provide an estimate of the cost and any extension of time required for completion of the works directly arising from the proposed change. The authority can review the capital required and its effect on the programme when deciding whether or not to proceed with the change. If, however, the authority wishes to proceed with the change, but disagrees with the estimate provided by the SPV, both parties have recourse to the disputes resolution procedure which can determine the costs of the change in question. This is in contrast to the FIDIC approach to variation where the engineer is given final authority in the matter.

Sub-clause (4) covers the situation where there are changes made to the law after the agreement has been entered into with the effect of requiring a change in the design or contents of the works. In this situation the change would be regarded as a works change in accordance with sub-clauses (1)-(3) and the SPV would be entitled to claim compensation for any increase in cost under that procedure. However, an important exception to this relates to certain prescribed changes in law which have been anticipated by the parties. These would normally be listed in a separate schedule and the SPV would not be entitled to any compensation for any additional costs or extension of the period of works arising from such changes. The SPV is deemed to have included the impact of such changes in its pricing structure.

\section{CHANGE IN LAW: FIDIC v UK PFI}

Both systems make provision for the impact of changes in law occurring after the commencement of a contract period.

\section{The FIDIC model}

Under the FIDIC model, there are four clauses which cater for any change of law or change in economic policy of the country where the project is being constructed. These clauses regulate the relationship between the parties under such circumstances. There are also supplementary clauses which provide for specific requirements of individual projects, depending on their status, nature and size.

The model implies an obligation on the contractor to comply with all statutes and regulations, including payments imposed under certain legal rules (FIDIC, Form of Contract, clause 26). There are two exceptions to these payments, which are the responsibility of the employer: first, any compensation payable for occupation of land by the works and, secondly, the obtaining of planning permission, zoning or other similar permission which is necessary in order for works to proceed.

The model also provides for fluctuations in the costs of labour and materials or any other matters which affect the cost of construction as a result of changes in legislation in the country where the project is to be constructed (clause 70.2). This must occur after the date 28 days prior to the latest date for submission of tenders for the contract. Fluctuations are easily calculated by the engineer, who determines any additional or reduced cost after 'due consultation' with the employer and the contractor, and the determined figure will be added to or deducted from the contract price.

\section{The UK PFI approach}

Changes in law which could have an impact on the project include increases in taxation; changes in health and safety regulations which require an alteration to buildings; changes to a specific law or regulation regarding the relevant sector (e.g. student accommodation, in the case of a university) or specific PFI project discriminatory legislation (e.g. windfall tax on PFI concessionaires). The impact of a change in law will vary not only with the type of change, but also with the phase of the project affected by it.

For example, during the construction phase the effect is likely to be limited to the cost to the SPV of making changes to the design, specification or quality, etc., of the building. A change in VAT amounts or minimum wage legislation, however, may affect the payments which the SPV has to make to its sub-contractors (in either phase).

During the operational period, a change in law could have a number of consequences, including increasing operating costs or reducing usage. In either scenario this might prejudice the SPV's ability to cover its running costs and debt service.

The SPV should be prepared to accept a significant proportion of the risk of a change in law. They should have considered the risk in preparing their bid. Usual business risks, such as a change in corporation tax, should not be passed back to the public sector. The public sector should consider offering a compensation payment to the SPV should the change incur costs exceeding an agreed figure. Furthermore, any increase in costs over a prescribed ceiling figure would permit either party to terminate the agreement.

Procedure in the event of a change in law is summarised below:

- where a change in law is likely to cause an increase in construction, operation and maintenance costs, the SPV must supply full written details of the anticipated effects of the change on their costs;

- agreement must then be reached between the parties on the percentage increase in costs the change will cause;

- if agreement is not reached, the percentage increase will be determined by the disputes resolution procedure;

- no compensation will be given to the SPV where the increase in costs falls below a prescribed limit;

- compensation will be given where the costs exceed the lower limit but do not exceed a prescribed upper limit;

- compensation will be calculated in accordance with a formula set out in a Schedule to the Concession Agreement;

- should the increase in costs exceed the prescribed upper limit, either party may terminate the agreement.

Unless the agreement is terminated, the SPV will be expected to carry out all its obligations under the terms of the Concession Agreement irrespective of whether or not agreement has been reached on the percentage increase figure or if a compensation payment is to be made.

\section{CONCLUSION}

There are significant differences between the approach taken by FIDIC and that taken by the UK in PFI contracts. This is mainly due to a change in the bargaining strength of the parties. 
Under the FIDIC model, the employer is either the public sector or a private entity, whereas in PFI projects in the UK only the public sector is using this route to build/finance infrastructure projects. The crucial factor, however, is that UK PFl deals are dependent on private funding; this means that the public sector's bargaining hand is weakened since private sector financiers will invariably want maximum protection for their investments. The structure of the deals is also very different since most PFI contracts are service-orientated. This means that the construction part of the agreement is not the most important feature of the contract and therefore the negotiating position of the parties differs accordingly. (c)

\title{
The selection of arbitrators: another view
}

\author{
by K V S K Nathan
}

\begin{abstract}
In the January 1999 issue of Amicus Curiae, David Winter OBE of Baker \& McKenzie in his article 'The selection of arbitrators' set out the process of choosing an arbitrator, which he divided into 12 points in his summary. Here, Dr K V S K Nathan responds to Mr Winter's article and expresses his own views on the topic.
\end{abstract}

$\mathrm{I}$ read with interest the paper by David Winter OBE on 'The selection of arbitrators' in Issue 13 of Amicus Curiae (January 1999). I agree entirely with the author except for the fact that, under the conditions that exist in the real world, the selection of arbitrators is made by people with an imperfect knowledge of the individual arbitrators and the nature of the dispute. In my opinion, the focus should be on the process of selection rather than on the individual arbitrator. The selection process should be seen as fair and neutral and respect the autonomy of the parties in dispute. The product of this process would lead to an ideal arbitration, if not the ideal arbitrator.

By themselves, considerations of psychology of the individual arbitrator, bias and independence, leadership qualities and acceptability to all partics can mean different things to different people, or indeed mean little in a world of intrigue and interest groups and divisive politics. Appearances can be very deceptive. In the terms expressed in the article, the ideal arbitrator, or for that matter the ideal judge in a court of law, is an elusive creature of our imagination.

\section{PARTY EXPECTATIONS}

Since arbitration is the creation of the parties in dispute, one should look at the expectations of the parties themselves in the selection of an arbitrator or arbitrators. Obviously the ideal arbitrator would be one who would faithfully follow the wishes of the parties in regard to the expeditious conduct of the arbitration and making of the award This would be consistent with the goal of arbitration, namely a binding award in dispute. However, there will be questions of fact as well as of law to be determined in an arbitration and, therefore, one has to accept that individual arbitrators, like individual judges in a court of law, can come quite honestly to different conclusions. There can be a whole range of valuc judgments to be made and arbitrators, like their counterparts in the courts of law, can vary widely in their perceptions of matters before them and of the credibility of witnesses, but that does not signify bias one way or another or disqualify them from being arbitrators and judges. I do not think that we want arbitrators to be clones of one another.

From the perspective of a party in dispute, the ideal arbitrator would be someone who would hopefully support the party's case in the matter in dispute. Where the party has the right to nominate an arbitrator, it is bound to look for someone who will perceive and interpret the facts and law of the case in a manner favourable to the party concerned. The party would be interested not only in the arbitrator's background qualifications and experience but also his or her views as expressed in a variety of contexts, such as public statements, law journals, previous awards and so on. There is nothing wrong in a party selecting as arbitrator someone whom he or she thinks would be sympathetic to his or her case. That the arbitrator thinks one way or another is not always an indication of bias but rather an illustration of his or her powers of reasoning and intellect. Reading the criteria listed in the article, one might be tempted to think that it may be prudent for arbitrators to keep their views on issues of the day to themselves, because the devil one does not know would seem to be better that the devil one knows. That would be harmful to the whole adjudicatory process, where onc is searching for the truth. Truth is most likely to be discovered 